Article

\title{
Structure, Mechanical and Optical Properties of Silicon-Rich Al-Si-N Films Prepared by High Power Impulse Magnetron Sputtering
}

\author{
Sergei Zenkin*(D), Fedor Konusov, Aleksandr Lauk, Denis Zelentsov and Stanislav Demchenko \\ Research School of High-Energy Physics, Tomsk Polytechnic University, Tomsk 634050, Russia; \\ konusov@tpu.ru (F.K.); lauk@tpu.ru (A.L.); z-denis07@mail.ru (D.Z.); stas.dem@mail.ru (S.D.) \\ * Correspondence: zen@tpu.ru
}

Received: 9 November 2018; Accepted: 16 January 2019; Published: 17 January 2019

\begin{abstract}
This article reports on the influence of the sputtering parameters (discharge voltage, average target power density) of a high power impulse magnetron discharge (HiPIMS) on the structure, mechanical and optical properties of silicon-rich $\mathrm{Al}-\mathrm{Si}-\mathrm{N}$ films. We show that with the change of a discharge target power density in the range of $30-120 \mathrm{~W} / \mathrm{cm}^{2}$, the hardness of the sputtered Al-Si-N films nonlinearly changes in the range of $22-29 \mathrm{GPa}$, while the concentration of the absorption centers changes in the range of $10^{18}-10^{20} / \mathrm{cm}^{3}$. The optical spectra of the HiPIMS sputtered films are completely different from the $\mathrm{Al}-\mathrm{Si}-\mathrm{N}$ films prepared by a direct current magnetron sputtering, with an absence of "monoenergetic" optical absorption centers, which are attributed to point defects.
\end{abstract}

Keywords: HiPIMS; Al-Si-N; silicon nitride; microstructure

\section{Introduction}

Aluminum-silicon nitride-based materials find a lot of applications in various fields such as electronics [1], optics [2], cutting tools [3], or light-emitting devises [4]. This wide use is due to the unique combination of its physical, electrical and mechanical properties. Al-Si-N materials show high hardness up to $30 \mathrm{GPa}$ [5], superior toughness [6], optical transparency in the visible range [7], and excellent stability under harsh conditions such as high temperature [8] or accelerated particles bombardment [9]. It has been shown that the structure and properties of $\mathrm{Al}-\mathrm{Si}-\mathrm{N}$ materials are highly sensitive to the method and parameters of their preparation. By changing the $\mathrm{Al} / \mathrm{Si}$ ratio, it is possible to tune a microstructure of the $\mathrm{Al}-\mathrm{Si}-\mathrm{N}$ composite from the crystalline through the nanocomposite to the fully amorphous state. After crossing approximately 12 at.\% of the silicon concentration sputtered films exhibit a completely X-ray amorphous structure of a Al-doped $\mathrm{Si}_{3} \mathrm{~N}_{4}$ [10]. Subsequent works have shown that this change of the microstructure strongly influences the mechanical and optical properties of the Al-Si-N composite [5]. Recent articles are mostly focused on the application of the high-power impulse magnetron sputtering (HiPIMS) to the Al-Si-N synthesis [11,12]. The main advantage of this technique is the fact of an extreme plasma ionization degree [13] leading to high mean particle energies (tens of eV) [14], a high dissociation of a reactive gas [15] and dense, void-free microstructure of sputtered films [16]. These advantages allow for smooth and optimized control of the structure and morphology of Al-Si-N sputtered thin films [17]. However, all reported data are focused on the Al-Si-N films with low ( $<20$ at.\%) silicon concentration. In this paper, we investigate the influence of HiPIMS parameters on the optical, mechanical and structural properties of the Al-Si-N system with a high silicon concentration. 


\section{Materials and Methods}

$\mathrm{Al}-\mathrm{Si}-\mathrm{N}$ films were sputtered using a round unbalanced magnetron equipped by an $\mathrm{Al} / \mathrm{Si}$ (25 at.\%/75 at.\%) target. The magnetron was powered by the HIPIMS power supply ( $1 \mathrm{kV}, 5 \mathrm{~kW}$, Applied Electronics, Tomsk, Russia). The base pressure $p_{0}$ in the evacuated deposition chamber was $8 \times 10^{-4} \mathrm{~Pa}$. We sputtered the Al-Si-N films on $\mathrm{Si}(100)$ and glass substrates under the following deposition conditions: discharge voltage $U_{\mathrm{d}}=700-1000 \mathrm{~V}$, pulse period $\tau=10 \mu \mathrm{s}$, pulse frequency $f=2 \mathrm{kHz}$, substrate temperature $T_{\mathrm{s}}=300{ }^{\circ} \mathrm{C}$, substrate-to-target distance $d_{\mathrm{s} \text { - }}=100 \mathrm{~mm}$, argon flow $\phi_{\mathrm{Ar}}=100 \mathrm{sccm}$, nitrogen flow $\phi_{\mathrm{N}}=100 \mathrm{sccm}$, argon pressure $p_{\mathrm{Ar}}=0.133 \mathrm{~Pa}$, and nitrogen pressure $p_{\mathrm{N}}=0.5 \mathrm{~Pa}$. The sputtering system allows us to control the magnetron sputtering voltage in the range of $U_{\mathrm{d}}=700-1000 \mathrm{~V}$ with the corresponding discharge current $I_{\mathrm{d}}=150-350 \mathrm{~A}$. The average target power density $w_{\mathrm{S}}$ was calculated as:

$$
w_{\mathrm{s}}=\frac{\frac{1}{T} \int_{0}^{T} U_{\mathrm{d}}(t) I_{\mathrm{d}}(t) \mathrm{d} t}{S}
$$

here, $T$ is the pulse period, $S$ is the target area $\approx 80 \mathrm{~cm}^{2}$.

Resulting average target power density $w_{\mathrm{s}}$ was in the range of $30-120 \mathrm{~W} / \mathrm{cm}^{2}$ for $U_{\mathrm{s}}=700-1000 \mathrm{~V}$ respectively. This strong sputtering power leads to a high ionization degree of the sputtering material [13]. In order to estimate the plasma ionization level at the various target power densities, we used a plasma optical emission spectroscopy (AvaSpec-ULS2048XL-EVO, Avantes, Apeldoorn, The Netherlands) and selected the characteristic lines of aluminum $\left(\mathrm{Al}^{+}(510 \mathrm{~nm}), \mathrm{Al}^{++}(607 \mathrm{~nm})\right)$, silicon $\left(\mathrm{Si}^{+}(615 \mathrm{~nm}), \mathrm{Si}^{++}(578 \mathrm{~nm})\right)$ and nitrogen $\left(\mathrm{N}^{+}(746 \mathrm{~nm})\right)$. The coating's cross-sectional morphology and elemental composition were studied using a scanning electron microscope equipped with an EDS detector (Quanta SEM, FEI, Hillsboro, OR, USA). Structural characteristics of the coatings were studied using X-ray diffraction (Shimadzu XRD 6000, Shimadzu, Kyoto, Japan) in the Bragg-Brentano configuration with $\mathrm{Cu} K \alpha(\lambda=0.154 \mathrm{~nm})$ radiation. Infrared spectra of the sputtered films were measured by the FTIR spectrometer (Nicolet 5700, Thermo Electron Corporation, Waltham, MA, USA). The density of the sputtered films was measured by the film mass divided by volume, where the film mass is calculated by the difference of the substrate-film system masses before and after the film deposition, and the volume is calculated by the multiplication of the film thickness and the area of the Si substrate.

\section{Results}

Figure 1a shows the experimental current-voltage diagram of the HiPIMS for $w_{\mathrm{s}}=120 \mathrm{~W} / \mathrm{cm}^{2}$. The resulted peak current $I_{\mathrm{d}}=350 \mathrm{~A}$ with the attributed discharge voltage $U_{\mathrm{d}}=1000 \mathrm{~V}$ gives a peak discharge power density up to $4.5 \mathrm{~kW} / \mathrm{cm}^{2}$. Figure $1 \mathrm{~b}$ shows the selected line intensities of the OES spectra for the target material atoms ( $\mathrm{Al}$ and $\mathrm{Si}$ ) and nitrogen atoms at the various discharge voltages and the corresponding average target power density.

Line intensities exponentially increase with the increasing of the discharge voltage, especially for ionized atoms at the higher ion charge states $\left(\mathrm{Al}^{++}\right.$and $\left.\mathrm{Si}^{++}\right)$with the change of a discharge voltage from 700 to $1000 \mathrm{~V}$ with the corresponding target power density change from 30 up to $120 \mathrm{~W} / \mathrm{cm}^{2}$. At the substrate floating potential $U_{\mathrm{f}} \approx-25 \mathrm{~V}$ that gives a strong ion bombardment of the growing film with the ion energies up to $80 \mathrm{eV}$ (up to $30 \mathrm{eV}$ of the ion initial energy [18]) and densification of the growing film, as shown in Figure 2. The density of the sputtered Al-Si-N films is correlated with their stoichiometry. The maximum density of the sputtered film deposited at $U_{\mathrm{d}}=900 \mathrm{~V}$ is related to the $\mathrm{Al}_{11} \mathrm{Si}_{31} \mathrm{~N}_{55}$ composition, giving the stoichiometry $\mathrm{AlN} / \mathrm{Si}_{3} \mathrm{~N}_{4}$. A higher increase of the discharge voltage leads to the intense bombardment by the high energy $\mathrm{N}^{+}$ions and enlarged nitrogen concentration in the growing film. For the film deposited at $U_{\mathrm{d}}=1000 \mathrm{~V}$, a resulted film composition $\mathrm{Al}_{11} \mathrm{Si}_{30} \mathrm{~N}_{58}$ gives an overstochiometric nitrogen concentration. Values of hardness of the sputtered films is also strongly correlated with the elemental composition. The maximum value of $H=29.3 \mathrm{GPa}$ 
is attributed to fully stoichiometric $\mathrm{AlN} / \mathrm{Si}_{3} \mathrm{~N}_{4}$, while the change of the stoichiometry leads to the decreasing of the Al-Si-N film hardness, as shown in Figure 2.
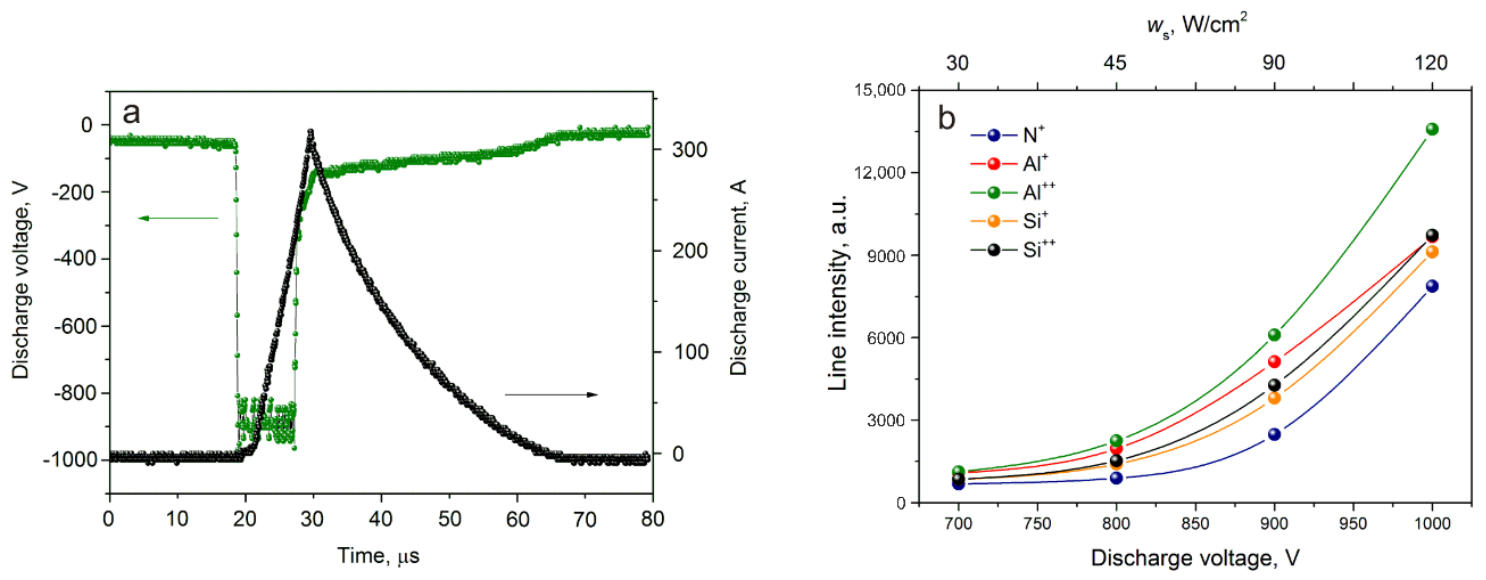

Figure 1. Single pulse characteristics (a) and optical emission spectroscopy intensities of selected lines (b) of HiPIMS discharge.

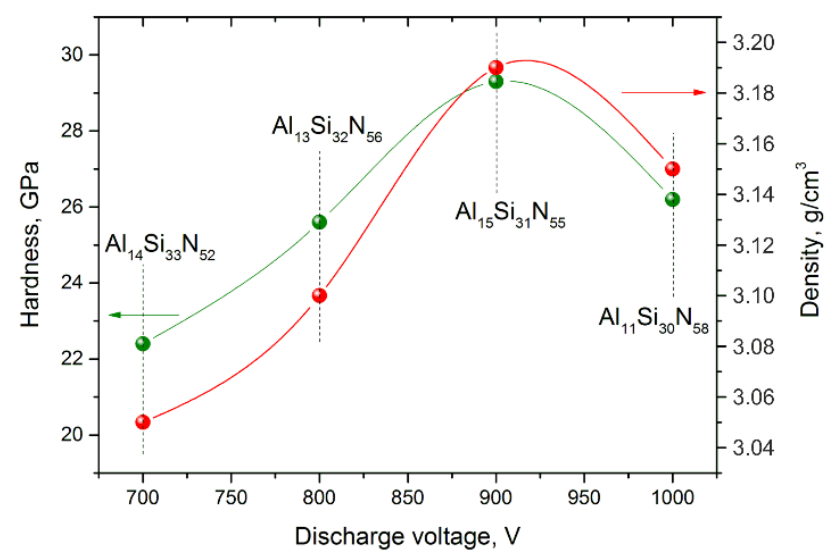

Figure 2. Hardness, density and elemental composition of sputtered Al-Si-N films that are dependent on the HiPIMS discharge voltage.

In order to characterize the structure of the sputtered films, we use FTIR measurements, X-ray diffraction and SEM measurements, as shown in Figure 3. Al-Si-N film prepared at $w_{\mathrm{S}}=30 \mathrm{~W} / \mathrm{cm}^{2}$ exhibits a fully amorphous structure in agreement with previously reported studies [5], as shown in Figure $3 \mathrm{~b}$. Additionally, Al-Si-N films are show the same cross-sectional morphology for all target power densities.

No lines of $\mathrm{AlN}$ or $\mathrm{Si}_{3} \mathrm{~N}_{4}$ also cannot be detected on the XRD measurements, as shown in Figure 3c. FTIR spectra of the same film consists of two peaks attributed to the Al-N stretching (780 and $1050 \mathrm{~cm}^{-1}$ ) and one strong peak of the Si-N stretching $\left(\sim 900 \mathrm{~cm}^{-1}\right)$, as shown in Figure 3a. While an increase of the sputtering power up to $120 \mathrm{~W} / \mathrm{cm}^{2}$ did not change the XRD pattern of Al-Si-N, on the FTIR spectra, one can detect a broadening of the Si-N peak at $\sim 900 \mathrm{~cm}^{-1}$ possibly due to the nitrogen dissolving.

A strong ion bombardment during the HiPIMS sputtering process leads to the high concentration of light absorption centers in the film. We found the correlation of light absorption center's concentration and deposition parameters by the measurement of optical absorption properties of the sputtered $\mathrm{Al}-\mathrm{Si}-\mathrm{N}$ films on the silica glass substrate. The spectral dependence of the absorption coefficient was calculated as:

$$
\alpha(h v)=D(h v) / d
$$


here, $D(h v)$ is a spectral characteristic of the optical density and $d$ is the film thickness. The thickness of all studied Al-Si-N films was $1 \pm 0.1 \mu \mathrm{m}$.

We estimated the absorption center's concentration by the Smacula-Dexter formula:

$$
N=0.87 \times 10^{17} \times \frac{n}{(n+2)^{2}} \times \frac{\gamma}{f} \times \alpha_{0}^{\prime}
$$

here, $n$ is the materials refractive index, $f$ is the oscillator order (in our case $f$ is assumed as 1 ), $\alpha_{0}^{\prime}$ is the absorption coefficient at the maximum of the local line with the center at $h v_{0}$ and half width $\gamma$.
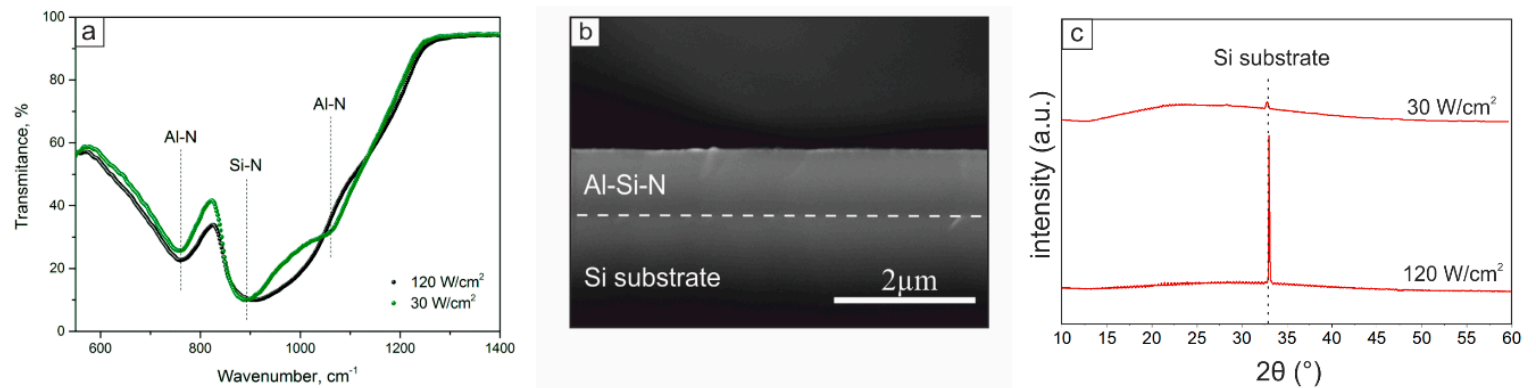

Figure 3. (a) FTIR spectra of Al-Si-N films prepared at $w_{\mathrm{s}}=30 \mathrm{~W} / \mathrm{cm}^{2}$ (green) and $120 \mathrm{~W} / \mathrm{cm}^{2}$ (black); (b) SEM image of the Al-Si-N film prepared at $w_{\mathrm{s}}=30 \mathrm{~W} / \mathrm{cm}^{2}$; (c) Diffraction patterns of Al-Si-N films prepared at $30 \mathrm{~W} / \mathrm{cm}^{2}$ HiPIMS discharge power (top) and Al-Si-N films prepared at $120 \mathrm{~W} / \mathrm{cm}^{2}$ HiPIMS discharge power (bottom).

In comparison with the Al-Si-N films previously sputtered by the DC and pulsed magnetron sputtering [19], the HiPIMS sputtered Al-Si-N films show absence of "monoenergetic" optical absorption centers, which are attributed to point defects, as shown in Figure 4. The absorption center's concentration for the HiPIMS sputtered film is an order of magnitude higher in comparison with the DC sputtered thin film at the same target power density $w_{\mathrm{s}}=30 \mathrm{~W} / \mathrm{cm}^{2}$ due to enlarged penetration of nitrogen ions during the sputtering process, as shown in Figure $4 \mathrm{a}$.
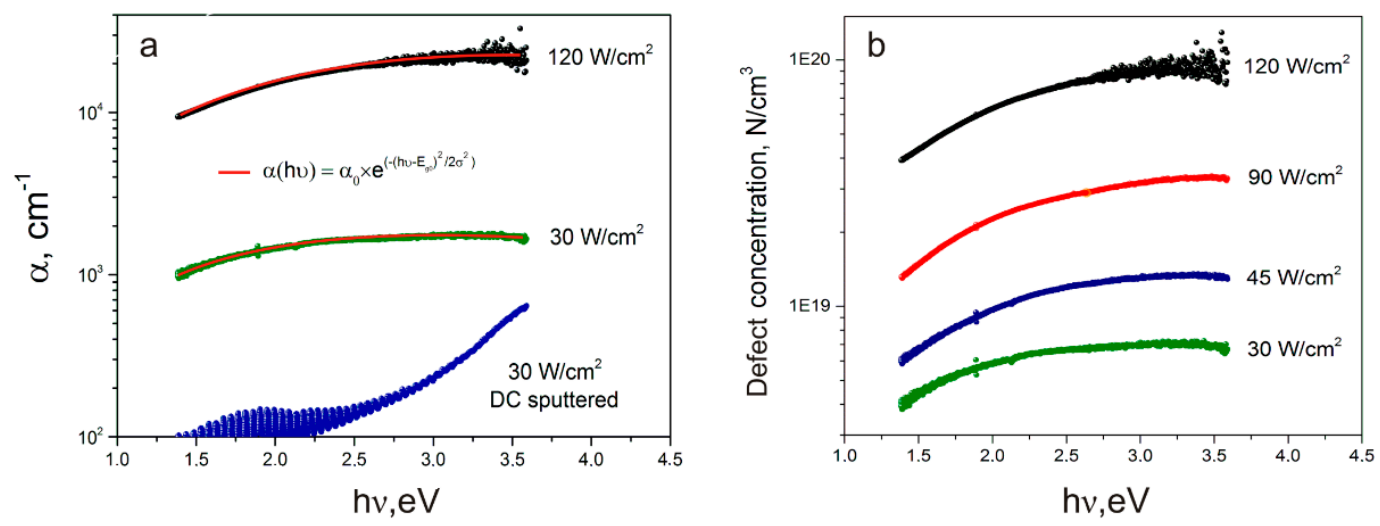

Figure 4. (a) Spectral dependence of the absorption coefficient; (b) absorption center's concentration in dependence with the average HiPIMS discharge power density.

We analyzed the spectral characteristics of the sputtered films by the inter-zone absorption model for the amorphous and highly defective materials [20]:

$$
\alpha(h v)=\alpha_{0}^{\prime \prime} \times \mathrm{e}^{-\left(h v-E_{g 0}\right)^{2} / 2 \sigma^{\prime 2}}
$$

Here, $\alpha_{0}^{\prime \prime}$ is a constant, $E_{g 0}$ is the median value of the materials band gap, and $\sigma^{\prime 2}$ is the dispersion of $E_{g}$, characterized by the defect disorder. 
Due to the good approximation of the experimental data by Equation (4), one can conclude that sputtered material consists of nanocrystals of Al-Si-N embedded into the amorphous $\mathrm{Si}_{3} \mathrm{~N}_{4}$ matrix, which is in agreement with FTIR and XRD data, as discussed above. The synthesized films show a direct band gap $E_{g 0}=2.98-3.44 \mathrm{eV}$ with the dispersion $\sigma^{\prime}=1.38-1.53$, as can be seen in Table 1 . The absorption coefficient and the corresponding absorption center's concentration increases with the increasing of an average magnetron target power density, as shown in Figure $4 \mathrm{~b}$, from $10^{18} / \mathrm{cm}^{3}$ for $w_{\mathrm{s}}$ $=30 \mathrm{~W} / \mathrm{cm}^{2}$ up to $10^{20} / \mathrm{cm}^{3}$ for $w_{\mathrm{s}}=120 \mathrm{~W} / \mathrm{cm}^{2}$. At the same time, the values of the median band gap and the optical gap increase with the correlated decreasing of the Urbach energy and the band gap dispersion of the film material, as shown in Table 1. Median band gap increases from $2.98 \mathrm{eV}$, which is a close value to the band gap of the fully amorphous silicon nitride [21] to the $3.44 \mathrm{eV}$, which is in correlation with increasing of the target power density possibly due to the formation of nanocrystalline $\mathrm{Si}_{3} \mathrm{~N}_{4}$ and AlN (band gaps 5.1 and $6.2 \mathrm{eV}$ respectively). Based on these data, one can conclude the reduction of the disorder in the growing material with the increasing of the magnetron target power density by the defects clustering.

Table 1. Optical characteristics of the sputtered Al-Si-N films in dependence with the HiPIMS target power density.

\begin{tabular}{ccccc}
\hline $\begin{array}{c}\text { Target Power Density } \\
\boldsymbol{w}\left(\mathbf{W} / \mathbf{c m}^{\mathbf{2}}\right)\end{array}$ & $\begin{array}{c}\text { Film Band Gap } \\
\boldsymbol{E}_{\boldsymbol{g} \mathbf{0}}(\mathbf{e V})\end{array}$ & $\begin{array}{c}\text { Band Gap Dispersion } \\
\boldsymbol{\sigma}^{\prime}(\mathbf{e V})\end{array}$ & $\begin{array}{c}\text { Urbach Energy } \\
\boldsymbol{E}_{\mathbf{U}}(\mathbf{e V})\end{array}$ & $\begin{array}{c}\text { Optical Gap } \\
\boldsymbol{E}_{\boldsymbol{g}^{\prime}}(\mathbf{e V})\end{array}$ \\
\hline 30 & 2.98 & 1.53 & 1.86 & 1.6 \\
45 & 3.14 & 1.40 & 1.48 & 1.8 \\
90 & 3.22 & 1.38 & 1.33 & 2.01 \\
120 & 3.44 & 1.5 & 1.15 & 2.04 \\
\hline
\end{tabular}

\section{Conclusions}

In conclusion, we show that mechanical and optical characteristics of the silicon-rich Al-Si-N films are heavily dependent on the sputtering voltage and power density of the HiPIMS discharge. The optimum value of sputtering power is around $w_{\mathrm{s}}=90 \mathrm{~W} / \mathrm{cm}^{2}$, and this gives the optimum stoichiometry $\mathrm{AlN} / \mathrm{Si}_{3} \mathrm{~N}_{4}$ and the highest hardness $H=29.3 \mathrm{GPa}$, while a higher increase of the sputtering power leads to the reduction of the hardness due to the enlarged amount of nitrogen in the growing film. The optical characteristics of the sputtered Al-Si-N films are correlated with the nitrogen concentration in the growing film. The HiPIMS sputtered Al-Si-N films show an absence of "monoenergetic" optical absorption centers, which are attributed to point defects, while the total concentration of the light absorption centers is an order of magnitude higher in comparison with the DC sputtered thin film at the same target power density.

Author Contributions: Methodology, S.Z.; Validation, S.Z. and F.K.; Formal Analysis, S.Z., A.L. and F.K.; Investigation D.Z. and S.D.; Writing-Original Draft Preparation, S.Z. and F.K.; Writing-Review and Editing, S.Z., A.L., S.D. and D.Z.

Funding: The research was funded by the Tomsk Polytechnic University within the framework of Tomsk Polytechnic University Competitiveness Enhancement Program grant.

Conflicts of Interest: The authors declare no conflict of interest.

\section{References}

1. Yang, M.; Wang, H.; Ma, X.; Gao, H.; Wang, B. Effect of nitrogen-accommodation ability of electrodes in $\mathrm{SiN}_{x}$-based resistive switching devices. Appl. Phys. Lett. 2017, 111, 233510. [CrossRef]

2. Guo, H.; Herkommer, C.; Billat, A.; Grassani, D.; Zhang, C.; Pfeiffer, M.H.P.; Weng, W.; Brès, C.; Kippenberg, T.J. Mid-infrared frequency comb via coherent dispersive wave generation in silicon nitride nanophotonic waveguides. Nat. Photonics 2018, 12, 330-335. [CrossRef]

3. Souza, J.V.C.; Nono, M.C.A.; Ribeiro, M.V.; Machado, J.P.B.; Silva, O.M.M. Cutting forces in turning of gray cast iron using silicon nitride based cutting tool. Mater. Des. 2009, 30, 2715-2720. [CrossRef] 
4. Negro, L.D.; Yi, J.H.; Michel, J.; Kimerling, L.C.; Chang, T.-W.F.; Sukhovatkin, V.; Sargent, E.H. Light emission efficiency and dynamics in silicon-rich silicon nitride films. Appl. Phys. Lett. 2006, 88, 233109. [CrossRef]

5. Musil, J.; Javdošňák, D.; Čerstvý, R.; Haviar, S.; Remnev, G.; Uglov, V. Effect of energy on the formation of flexible hard Al-Si-N films prepared by magnetron sputtering. Vacuum 2016, 133, 43-45. [CrossRef]

6. Shen, Z.; Zhao, Z.; Peng, H.; Nygren, M. Formation of tough interlocking microstructures in silicon nitride ceramics by dynamic ripening. Nature 2002, 417, 266-269. [CrossRef] [PubMed]

7. Nishiyama, N.; Ishikawa, R.; Ohfuji, H.; Marquardt, H.; Kurnosov, A.; Taniguchi, T.; Kim, B.; Yoshida, H.; Masuno, A.; Bednarcik, J.; et al. Transparent polycrystalline cubic silicon nitride. Sci. Rep. 2017, 7, 44755. [CrossRef]

8. Musil, J.; Remnev, G.; Legostaev, V.; Uglov, V.; Lebedynskiy, A.; Lauk, A.; Procházka, J.; Haviar, S.; Smolyanskiy, E. Flexible hard Al-Si-N films for high temperature operation. Surf. Coat. Technol. 2016, 307, 1112-1118. [CrossRef]

9. Sergeev, V.; Psakhie, S.; Chubik, P.; Cherniavsky, A.; Soloviev, V.; Solntsev, V.; Khristenko, Y. Magnetron sputtering of $\mathrm{Si}-\mathrm{Al}-\mathrm{N}$ nanocomposite coatings on quartz for protection against impacts of high speed microparticles. Vacuum 2017, 143, 454-457. [CrossRef]

10. Pélisson, A.; Parlinska-Wojtan, M.; Hug, H.J.; Patscheider, J. Microstructure and mechanical properties of Al-Si-N transparent hard coatings deposited by magnetron sputtering. Surf. Coat. Technol. 2007, 202, 884-889. [CrossRef]

11. Jiang, X.; Yang, F.; Chen, W.; Lee, J.; Chang, C. Effect of nitrogen-argon flow ratio on the microstructural and mechanical properties of $\mathrm{AlSiN}$ thin films prepared by high power impulse magnetron sputtering. Surf. Coat. Technol. 2017, 320, 138-145. [CrossRef]

12. Ding, J.C.; Wang, Q.M.; Liu, Z.R.; Jeong, S.; Zhang, T.F.; Kim, K.H. Influence of bias voltage on the microstructure, mechanical and corrosion properties of AlSiN films deposited by HiPIMS technique. J. Alloy. Compd. 2019, 772, 112-121. [CrossRef]

13. Anders, A. Tutorial: Reactive high power impulse magnetron sputtering (R-HiPIMS). J. Appl. Phys. 2017, 121, 171101. [CrossRef]

14. Yang, Y.; Tanaka, K.; Liu, J.; Anders, A. Ion energies in high power impulse magnetron sputtering with and without localized ionization zones. Appl. Phys. Lett. 2015, 106, 124102. [CrossRef]

15. Belosludtsev, A.; Houška, J.; Vlček, J.; Haviar, S.; Čerstvý, R.; Rezek, J.; Kettner, M. Structure and properties of Hf-O-N films prepared by high-rate reactive HiPIMS with smoothly controlled composition. Ceram. Int. 2017, 43, 5661-5667. [CrossRef]

16. Cemin, F.; Abadias, G.; Minea, T.; Furgeau, C.; Brisset, F.; Solas, D.; Lundin, D. Benefits of energetic ion bombardment for tailoring stress and microstructural evolution during growth of $\mathrm{Cu}$ thin films. Acta Mater. 2017, 141, 120-130. [CrossRef]

17. Pélisson-Schecker, A.; Hug, H.J.; Patscheider, J. Morphology, microstructure evolution and optical properties of Al-Si-N nanocomposite coatings. Surf. Coat. Technol. 2014, 257, 114-120. [CrossRef]

18. Jouan, P.; le Brizoual, L.; Ganciu, M.; Cardinaud, C.; Tricot, S.; Djouadi, M. HiPIMS ion energy distribution measurements in reactive mode. IEEE Trans. Plasma Sci. 2010, 38, 3089-3094. [CrossRef]

19. Kabyshev, A.V.; Konusov, F.V.; Lauk, A.L.; Lebedynskiy, A.M.; Legostaev, V.N.; Smolyanskiy, E.A. Optical absorption peculiarities of Al-Si-N coatings produced by magnetron sputtering. Key Eng. Mater. 2016, 712, 3-8. [CrossRef]

20. Konusov, F.V.; Kabyshev, A.V.; Remnev, G.E. Optical properties of GaAs films deposited via pulsed ion ablation. J. Surf. Invest. 2011, 5, 228-235. [CrossRef]

21. Wang, Q.; Ward, S.; Gedvilas, L.; Keyes, B.; Sanchez, E.; Wang, S. Conformal thin-film silicon nitride deposited by hot-wire chemical vapor deposition. Appl. Phys. Lett. 2004, 84, 338-340. [CrossRef]

(C) 2019 by the authors. Licensee MDPI, Basel, Switzerland. This article is an open access article distributed under the terms and conditions of the Creative Commons Attribution (CC BY) license (http://creativecommons.org/licenses/by/4.0/). 